\title{
Functional characterization of three clones of the human intestinal Caco-2 cell line for dietary lipid processing
}

\author{
Séverine Salvini ${ }^{1}$, Monique Charbonnier ${ }^{1}$, Catherine Defoort ${ }^{1,2}$, Christian Alquier ${ }^{1}$ and Denis Lairon $^{1 *}$ \\ ${ }^{1}$ Unité 476 INSERM, Nutrition humaine et lipides, 18 Avenue Mozart, 13009 Marseille, France \\ ${ }^{2}$ Laboratoire de Chimie Analytique, Faculté de Pharmacie, 27 Bd J Moulin, 13005 Marseille, France
}

(Received 24 May 2001 - Revised 18 September 2001 - Accepted 5 November 2001)

\begin{abstract}
We aimed to improve the use of the human intestinal Caco-2 cell line for studying dietary lipid and cholesterol processing by using isolated pure clones (Chantret et al. 1994). Three clones (TC7, PD7 and PF11) were grown as monolayers on semi-permeable filters and compared for cell viability, fatty acid and cholesterol apical uptake or basolateral secretion, apolipoprotein B-48 basolateral secretion and 3-hydroxy-3-methylglutaryl (HMG)-CoA reductase activity. The TC7 clone showed the best viability upon apical incubation with mixed micelles and should be preferred for routine work. Short-term $(3 \cdot 0 \mathrm{~h})$ rates of apical uptake of cholesterol were not different with the three clones, whereas the rate of apical uptake of oleic acid (18:1) was lower $(P<0.05)$ with PF11 $(250.6 \mathrm{nmol} / \mathrm{mg})$ and the basolateral secretion of cholesterol and oleic acid was lower with the TC7 clone $(0.40$ and $29.1 \mathrm{nmol} / \mathrm{mg}$ respectively). The secretion of apolipoprotein B-48 basolaterally was about 2-fold lower than from PD7 clone. The basal levels of HMG-CoA reductase activity were significantly different $(P<0.05$; TC7 $>$ PF11 $>$ PD7 $)$. The down-regulation of the enzyme activity was moderate (range $13.8-21.0 \%$ ) and comparable in the presence of apical micellar cholesterol, but was much marked upon basolateral incubation with LDL (range 34.0-53.6\%), especially for the PD7 clone. In conclusion, the Caco-2 clones characterized here proved to be particularly suitable for studying lipid nutrients processing. Because these three clones exhibit some different metabolic capabilities, they provide a new tool to study intestinal response to lipid nutrients.
\end{abstract}

Cholesterol: Lipids: Absorption: Intestine

Lipid nutrients, through their handling by the digestive tract, are key determinants of body-lipid homeostasis. Cholesterol homeostasis is maintained by the balance between dietary cholesterol absorption, endogenous cholesterol synthesis and excretion of biliary cholesterol and bile acids. Moreover, postprandial occurrence and metabolism of triacylglycerol-rich lipoproteins is a key determinant of lipoprotein accumulation in the circulation (Mamo et al. 1998). The small intestine, which is responsible for regulating the absorption of dietary and biliary cholesterol, plays a role in de novo cholesterol synthesis and secretion of chylomicrons into the circulation (Hussain, 2000). Nevertheless, the complex and multi-step process involved in intestinal absorption and re-secretion of dietary cholesterol as shown in human subjects (Beaumier-Gallon et al. 2001) remains poorly understood. Recent studies suggest that cholesterol absorption is saturable (Sehayek et al. 1998) and genetically controlled, and support a protein-mediated mechanism for cholesterol uptake by the intestinal mucosa (Hauser et al. 1998). In addition, the mechanisms by which dietary lipids are uptaken by enterocytes, processed and secreted, are still under investigation (Hussain, 2000).

The differentiated human intestine Caco- 2 cell line has become widely used as an in vitro model (Levy et al. 1995) for studying enterocyte functions, given its ability to express relatively high levels of digestive brush-border enzymes and to display other structural and functional characteristics of absorptive villus cells (Pinto et al. 1983). Regarding lipids, free fatty acids are efficiently absorbed and incorporated into phospholipids and triacylglycerols (Mehran et al. 1997) and cholesterol is uptaken under micellar form (Homan \& Hamelehle, 1998). Caco-2 cells are capable of apolipoprotein (Apo) B mRNA-editing under defined conditions resulting in secretion of both ApoB-48 and ApoB-100, as structural proteins of two classes of lipoproteins with distinct density (van Greevenbroek et al. 2000). The basolateral lipid secretion is

\footnotetext{
Abbreviations: Apo, apolipoprotein; HMG, 3-hydroxy-3-methylglutaryl; LDH, lactate dehydrogenase.

* Corresponding author: Dr Denis Lairon, fax +33 4917515 62, email lairon@marseille.inserm.fr
} 
reported to be limited, but depends on Caco- 2 cells used, the level of differentiation and incubation conditions (Mehran et al. 1997). Because of its heterogeneity, the parental Caco-2 population has been shown to vary with the number of passages of the cell lines. Chantret et al. (1994) have isolated different clones from early and late passages of the parental Caco- 2 cell line. Three isolated clonal lines (TC7, PF11 and PD7) differ significantly for monolayer morphology, glucose consumption rate, glycogen accumulation and sucrase-isomaltase expression. Thus, we aimed in the present study to characterize the major functions of these three Caco-2 clones regarding dietary cholesterol and fatty acid uptake, cholesterol synthesis, ApoB-48 content and secretion of triacylglycerol-rich lipoproteins. The final objective was to evaluate how these clones can model enterocyte dietary lipid processing. The results obtained show that these wellcharacterized clones provide a new tool to study intestinal absorption and response to dietary cholesterol and fatty acids.

\section{Materials and methods}

\section{Cell cultures}

Three clones of the Caco- 2 cell line, originally derived from human colonic adenocarcinoma, were studied. Clonal lines TC7, PD7 and PF11 were a gift from Dr M. Rousset and A. Zweibaum (Paris, France) and were used between passages 48 and 60 (Chantret et al. 1994). Clonal line TC7 was originally a late passage (passage 198) and clonal lines PD7 and PF11 were originally an early passage (passage 29).

Stocks of Caco- 2 cells were grown on $25 \mathrm{~cm}^{2}$ plastic flasks in Dulbecco's modified Eagle's medium containing $4.5 \mathrm{~g}$ glucose/1, supplemented with nonessential amino acids $(10 \mathrm{~g} / \mathrm{l})$ and heat-inactivated $\left(30 \mathrm{~min}, 56^{\circ} \mathrm{C}\right)$ fetal calf serum $(200 \mathrm{ml} / \mathrm{l})$ in a $10 \% \mathrm{CO}_{2}$ humidified incubator at $37^{\circ} \mathrm{C}$. In all cases, media were changed $2 \mathrm{~d}$ after seeding and daily afterwards. Monolayers were subcultured when they reached about $70-80 \%$ confluence, at a density of $0.25 \times 10^{6}$ cells for TC7 and PD7 and a density of $0.35 \times$ $10^{6}$ cells for PF11 using trypsin $(2 \cdot 5 \mathrm{~g} / \mathrm{l})$-EDTA $(1 \mathrm{~mm})$.

For the experiments, cells were seeded at $1 \times 10^{6}$ cells per $23.1 \mathrm{~mm}$ diameter polyethylene terephthalate culture insert $(0.1 \mu \mathrm{m}$ pore size $)$. The inserts were fitted in six well culture plates allowing separate access to the upper and lower surfaces of the cell monolayers $(1 \mathrm{ml}$ and $2 \mathrm{ml}$, apical and basolateral culture medium respectively). The experiments were performed on day 21 after plating, i.e. after cells reached confluence and made a tight monolayer as checked by transepithelial electrical resistance. All cell culture media were purchased from GIBCO BRL (Cergy Pontoise, France). Other cell culture materials were obtained through TPP (Polylabo, Strasbourg, France) and Becton Dickinson (Le Pont de Claix, France).

\section{Measurement of monolayer integrity}

Phenol Red diffusion. Cells were incubated with PhenolRed apical medium containing or not mixed micelles. The diffusion of Phenol Red across the monolayer from the upper compartment to the lower one was determined by measuring absorbance at $546 \mathrm{~nm}$ after $2.5 \mathrm{~h}$ incubation at $37^{\circ} \mathrm{C}$ in the two compartments (Halleux \& Schneider, 1991).

Propidium iodide. The fluorescent agent propidium iodide can stain the cell nucleus but does not penetrate normal living cell membranes. Thus, it was used to discern cell viability and the effects of additives, incubated with culture medium with or without mixed micelles for $16.0 \mathrm{~h}$, on cell membrane permeability (Anderberg \& Artursson, 1993). Monolayers were examined under the fluorescence microscope (excitation $536 \mathrm{~nm}$, emission $617 \mathrm{~nm}$ when bound to DNA).

Lactate dehydrogenase release. To detect any discrete monolayer disruption, the release of the cytosolic marker lactate dehydrogenase (LDH) in the apical medium was measured after different incubation times with mixed micelles. LDH activity was determinated at $37^{\circ} \mathrm{C}$ using a colorimetric kit (Roche Diagnostic, Mannheim, Germany). The absorbance was measured at a wavelength of $365 \mathrm{~nm}$. LDH activity was expressed in IU/l. Total LDH activity was obtained by treating cells with Triton X-100 (1 ml/1; Sigma-Aldrich, St Quentin Fallavier, France) and sonication (Chong et al. 2000).

\section{Experimental procedures and lipid uptake determinations}

Mixed micelles. Appropriate aliquots of stock solutions in chloroform-methanol $(2: 1, \mathrm{v} / \mathrm{v})$ of $\mathrm{L}-\alpha$-phosphatidylcholine (from egg yolk), 1-monooleoyl-rac-glycerol (18:1, (cis)-9), cholesterol and radiolabelled lipids (cholesterol and/or oleic acid) were taken, dried under $\mathrm{N}_{2}$ and lyophilized to obtain a lipid film. $\left[1,2,6,7-{ }^{3} \mathrm{H}(\mathrm{N})\right]$ cholesterol $(3100 \mathrm{GBq} / \mathrm{mmol})$ was purchased from Amersham (Bucks, UK), $\left[4-{ }^{14} \mathrm{C}\right]$ cholesterol $(1.9 \mathrm{GBq} / \mathrm{mmol})$ and $\left[9,10-{ }^{3} \mathrm{H}(\mathrm{N})\right]$ oleic acid $(185 \cdot 0 \mathrm{GBq} / \mathrm{mmol})$ were purchased from New England Nuclear (Boston, MA, USA). Sodium taurocholate and sodium oleate solubilized in culture medium were added and solution was stirred until clear. Final micellar concentrations were: $5 \mathrm{~mm}$-sodium taurocholate, $2 \mathrm{~mm}$-egg phosphatidylcholine, $0.5 \mathrm{~mm}$-sodium oleate, 0.1 mM-cholesterol, 0.03 mM-monooleoylglycerol. Cholesterol (purity $990 \mathrm{~g} / \mathrm{kg}$ ), L- $\alpha$-phosphatidylcholine (purity $990 \mathrm{~g} / \mathrm{kg}$ ), 1-monooleoyl-rac-glycerol (18:1, (cis)-9), oleic acid (cis-9-octadecenoic acid) sodium salt (purity $950 \mathrm{~g} / \mathrm{kg}$ ) and taurocholic acid sodium salt (purity $970 \mathrm{~g} / \mathrm{kg}$ ) were purchased from Sigma-Aldrich.

Cells were incubated with Dulbecco's modified Eagle's medium containing delipidated fetal calf serum for $24 \mathrm{~h}$ before experiments. To determine cholesterol and/or oleic acid uptake, cells were incubated at their apical side with radiolabelled mixed micelles. At the specified times, media were removed and aliquots were used to measure radioactivity. Cells were washed twice with $2 \times 1 \mathrm{ml}$ PBS and lipids were extracted from cells with hexaneisopropanol $(3: 2,(\mathrm{v} / \mathrm{v})$. Proteins were solubilized from cells with $2 \times 1 \mathrm{ml} 0.1 \mathrm{M} \mathrm{NaOH}$ and measured by the bicinchoninic acid technique (BCA kit; Pierce, Rockford, IL, USA). The absorbance was read at $562 \mathrm{~nm}$ on ninetysix well microtitre plates (Nunc; Polylabo, Strasbourg, 
France) with a microtitre plate reader (Labsystem; Life Sciences International, Cergy Pontoise, France).

Isolation of lipoproteins by ultracentrifugation. Lipoproteins with either low density $(\mathrm{d}<1.063 \mathrm{~g} / \mathrm{ml})$ or high density $(1.063<\mathrm{d}<1.21 \mathrm{~g} / \mathrm{ml})$ were isolated from basolateral medium using a TL100 ultracentrifuge (Beckman Instruments, Palo Alto, CA, USA) with a TLA-100.3 fixed rotor angle as described by Dubois et al. (1998). LDL particles $(1.006<\mathrm{d}<1.063 \mathrm{~g} / \mathrm{ml})$ were isolated from a human fasting plasma sample as described by Dubois et al. (1998).

Apolipoprotein B-48. ApoB-48 was quantified in cellular extracts and basolateral secretion medium after $3 \cdot 0 \mathrm{~h}$ cell incubation with mixed micelles by a competitive ELISA method adapted from a method recently developed to assay human plasma ApoB-48 (Lorec et al. 2000).

3-Hydroxy-3-methylglutaryl-CoA reductase activity. 3Hydroxy-3-methylglutaryl (HMG)-CoA reductase activity was measured in the three Caco- 2 cell clones in the basal state or after $1.5 \mathrm{~h}$ cholesterol incubation. Cholesterol was provided to cells either as unlabelled mixed micelles at the apical side (as described earlier) or as human LDL $(100 \mu \mathrm{g} / \mathrm{ml})$ at the basolateral side. After washing, cells were scraped and lysed in the non-ionic detergent Igepal $(250 \mathrm{ml} / \mathrm{l})$ purchased from Sigma-Aldrich.

According to a published method (Brown et al. 1973), the supernatant fraction obtained was incubated with $\left[{ }^{14} \mathrm{C}\right] \mathrm{HMG}-\mathrm{CoA}$ in the presence of NADPH. The $\left[{ }^{14} \mathrm{C}\right]$ mevalonolactone formed was isolated after elution in an anion exchange resin micro-column (Bio-Rex 5 Resin, 100-200 mesh; Biorad, Missisanga, Ontario, Canada). Radioactivity was quantified and recovery was estimated using $\left[{ }^{3} \mathrm{H}\right]$ mevalonolactone as an internal standard. DL-3-[Glutaryl-3- $\left.{ }^{14} \mathrm{C}\right] \mathrm{HMG}-\mathrm{CoA} \quad(2 \cdot 1 \mathrm{GBq} /$ $\mathrm{mmol}$ ) and $(R S)-\left[5-{ }^{3} \mathrm{H}(\mathrm{N})\right]$ mevalonolactone (1073 GBq/ mmol) were purchased from New England Nuclear.

Radioactivity measurements. ${ }^{3} \mathrm{H}$ and ${ }^{14} \mathrm{C}$ radioactivity were measured in aqueous media by dual-liquid scintillation counting with an external standard for quench correction (TRi-Carb 1600 Packard, Meriden, CT, USA) in the presence of Emulsifier Safe (Packard, Groningen, The Netherlands). For all organic samples, Insta-Fluor was used (Packard).

\section{Statistical analysis}

The results are presented as mean values with their standard errors for five replicates. Statistical determinations were performed using one-way ANOVA and differences among groups were examined using Fischer's test $(P<0.05)$ using the Stateview II Micro Computer Program (Abacus, Berkeley, CA, USA).

\section{Results}

\section{Cell membrane integrity}

Phenol Red diffusion. A negligible Phenol Red diffusion across the monolayer was observed with the three Caco-2 clones incubated with or without mixed micelles (about 3 $\%$ ) with no difference between clones.

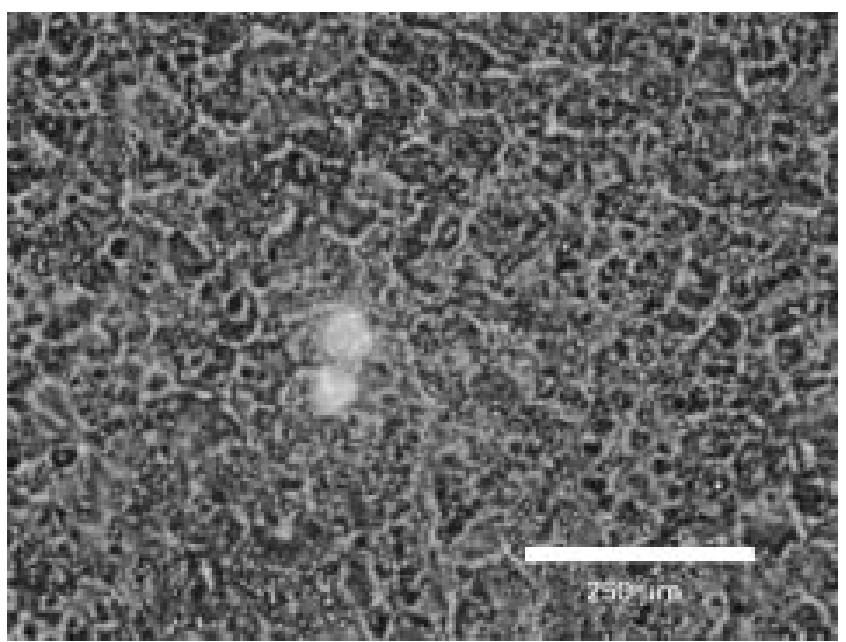

Fig. 1. Membrane integrity assay using the fluorescent marker propidium iodide: stain with propidium iodide of cell-damaged nucleus after $16.0 \mathrm{~h}$ mixed micelles incubation. Cells were grown as described on p. 212. After $16.0 \mathrm{~h}$ incubation with mixed micelles, monolayers were incubated apically with propidium iodide for $3 \mathrm{~min}$. After fixing and washing, monolayers were examined under fluorescence microscope. A negligible nucleus fluorescence was observed in all clones compared (TC7 clone picture presented only).

Propidium iodide. After $16 \mathrm{~h}$ micelles incubation, a weak nucleus fluorescence was observed upon microscopic observation (Fig. 1). A maximum of ten stained nuclei per filter was observed, indicating a very good cell viability.

Lactate dehydrogenase assay. The activity of $\mathrm{LDH}$ released into the extracellular medium when the cell membrane is damaged was measured in apical medium before and after different incubation times $(0 \cdot 0,0 \cdot 5,2 \cdot 0$, $5 \cdot 0,10 \cdot 0,16 \cdot 0 \mathrm{~h})$ with mixed micelles as shown in Fig. 2. Before mixed micelles incubation, LDH activity for clonal lines TC7, PF11 and PD7 were 387, 633 and 300 IU/1 respectively. For the three clones, we observed an increase in $\mathrm{LDH}$ concentration with incubation times from 0.0 to $16 \cdot 0 \mathrm{~h}$. After short incubation times $(0 \cdot 0-2 \cdot 0 \mathrm{~h}), \mathrm{LDH}$ activity increased moderately for TC7 $(62 \%)$ as compared with PF11 (112\%) and PD7 clones (221\%) $(P<0.05)$. After $16 \cdot 0 \mathrm{~h}$ incubation, the apical LDH activity released was significantly lower $(P<0.05)$ for TC7 $(1130 \mathrm{IU} / \mathrm{l})$ than for PF11 and PD7 (1660 and 1540 IU/1 respectively). A maximum LDH release of 2537 IU/l was observed after cell treatment by Triton $\mathrm{X} 100^{\circledR}$ (Sigma-Aldrich) and sonication (Chong et al. 2000).

\section{Apical uptake and basal secretion of cholesterol and oleic acid}

The uptake of cholesterol and oleic acid by the three Caco-2 clones after different incubation times $(0 \cdot 5,1 \cdot 5,3 \cdot 0$, 6.0 and $12.0 \mathrm{~h}$ ) with mixed micelles at the apical side is shown in Fig. 3. Increase in cholesterol uptake was linear until $6.0 \mathrm{~h}$ (Fig. 3(A)) and tended to plateau for a longer incubation time $(12.0 \mathrm{~h})$. After $12.0 \mathrm{~h}$, the PF11 and PD7 clones exhibited a significantly higher $(P<0.05)$ cellular content of radiolabelled cholesterol than TC7. For the three clones, the increase in cellular oleic acid incorporation was 


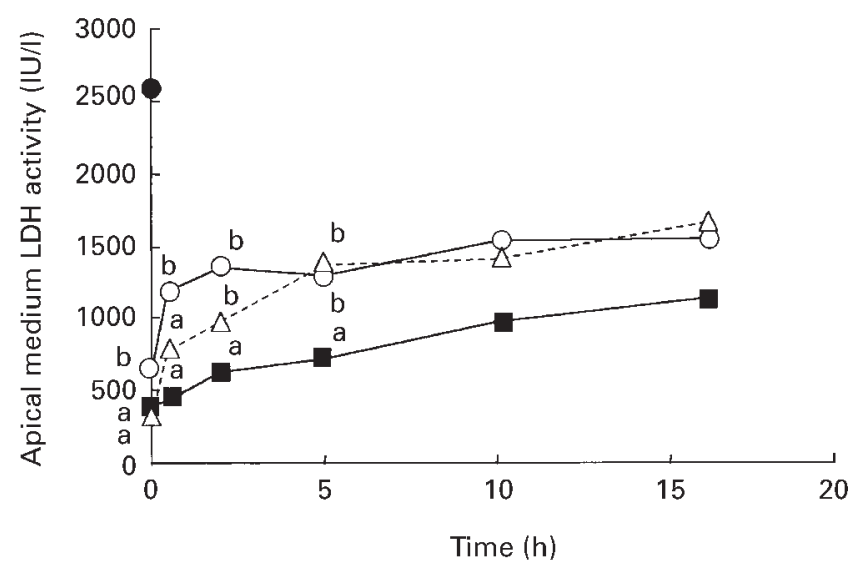

Fig. 2. Membrane integrity assay for Caco-2 clones: apical lactate dehydrogenase (LDH) activity for TC7 (-口-), PF11 (-O-) and PD7 $(-\Delta-)$ after $0.0,0.5,2.0,5 \cdot 0,10.0$ and $16.0 \mathrm{~h}$ apical incubation with mixed micelles. Clonal lines were cultured on filters in Dulbecco's modified Eagle's medium containing fetal calf serum $(200 \mathrm{ml} / \mathrm{l})$ and nonessential amino acids $(10 \mathrm{~g} / \mathrm{l})$ for $21 \mathrm{~d}$. Cells were preincubated with medium without lipid for $24 \mathrm{~h}$ before the experiment. LDH activity was determined on apical media at $37^{\circ} \mathrm{C}$ using a colorimetric kit. Absorbance was read at $365 \mathrm{~nm}$ and results expressed in IU/I. Total releasable LDH activity was measured after treating cells with Triton X-1001 ml/l; Sigma-Aldrich, St Quentin Fallavier, France and sonication ( $\mathbf{\square}, 100 \%$ ) (Chong et al. 2000. For details of procedures, see p. 212. Values are means for three replicates with standard errors shown by vertical bars. ${ }^{\mathrm{a}, \mathrm{b}}$ Mean values with unlike superscript letters were significantly different at a given time point $(P<0.05)$.

linear until 6.0 h (Fig. 3(B)), with no further change for a longer incubation period $(12.0 \mathrm{~h})$. At time $6.0 \mathrm{~h}$, TC7 showed a higher cellular oleic acid content than PF11 and PD7.

The basolateral cholesterol secretion by the three clones was determined at specified times of micelles incubation (Fig. 3(C)). The basolateral cholesterol secretion increased linearly from 0.5 to $12.0 \mathrm{~h}$. For shorter incubation times (i.e. $3 \cdot 0 \mathrm{~h}$ ), no difference was observed between clones whereas after $12.0 \mathrm{~h}$, PD7 and PF11 clones exhibited a significantly higher basolateral cholesterol secretion. After $3.0 \mathrm{~h}$, the relative amounts of radiolabelled cholesterol secreted basolaterally by TC7, PD7 and PF11 in lipoproteins with low density were $42 \cdot 1,50.7$ and $32.5 \%$ of total, the rest being secreted as HDL. When the cells were incubated for $1 \cdot 0-2 \cdot 0 \mathrm{~h}$ with mixed micelles no difference between clones was observed for the basolateral oleic acid secretion (Fig. 3(D)). Conversely, after 6.0 or $12.0 \mathrm{~h}$, the PD7 and PF11 clones exhibited a significantly higher basolateral oleic acid concentration than TC7. After $3.0 \mathrm{~h}$, the TC7, PD7 and PF11 clones basolaterally secreted $55.2,59.0$ and $42.0 \%$ radiolabelled oleic acid in lipoproteins with low density $(\mathrm{d}<1.063 \mathrm{~g} / \mathrm{ml})$ respectively, the rest being secreted as HDL. The radiolabelled oleic acid:cholesterol molar ratios in lipoproteins with low density were not different with the three clones (mean values: TC7 116.0, PD7 109.4, PF11 109.1).

\section{Cellular and basolateral apolipoprotein B-48}

The ApoB-48 concentration in cellular extracts and basal media after $3.0 \mathrm{~h}$ incubation with mixed micelles was determined, as shown in Fig. 4. The ApoB-48 concentration in cellular extracts was not different for the three clones. Conversely, TC7 and PF11 clonal lines secreted into the basolateral medium comparable amounts of ApoB48 which were more than 2-fold greater than the amount of ApoB-48 secreted by the PD7 clone. The radiolabelled oleic acid:ApoB-48 molar ratios in secreted lipoproteins with low density were $2 \cdot 8$ - and 3.2-fold higher with PD7 than TC7 and PF11 respectively. At the same time, the radiolabelled cholesterol:ApoB-48 molar ratios were 2.9and 3.2-fold higher with PD7 than TC7 and PF11 respectively.

\section{Cellular 3-hydroxy-3-methylglutaryl-CoA reductase activity and cholesterol uptake}

TC7 cells, in the absence of incubation with mixed micelles apically, exhibited a significantly higher level of HMG-CoA reductase activity than PF11 and more markedly than PD7 cells, as shown in Fig. 5. After $1.5 \mathrm{~h}$ apical incubation with mixed micelles containing 0.1 mM-cholesterol, HMG-CoA reductase activity level was comparably down-regulated in the three clones to about $80 \%$ of respective controls value (Fig. 5). After a $1.5 \mathrm{~h}$ basal incubation with LDL $(100 \mu \mathrm{g} / \mathrm{ml})$, the HMGCoA reductase activity was more markedly down-regulated in the three clones (Fig. 5), the residual enzyme activities being $60 \cdot 2,46.2$ and $60.9 \%$ of controls for TC7, PD7 and PF11 clones respectively.

\section{Discussion}

The aim of the present study was to develop new experimental models for nutrition research by comparing the capability of three different clones of the human intestine Caco- 2 cell line to take up and secrete dietary cholesterol and fatty acids, and to synthesize cholesterol. While the parental Caco-2 cell line is most generally used for studying lipid processing (Trotter et al. 1996; Field et al. 1997; Mehran et al. 1997; van Greevenbroek et al. 2000), we thought it very useful to employ pure clones to avoid cell line alteration and heterogeneity, which are dramatically amplified upon passages. Moreover, some specific features of a given clone could be used to exacerbate or weaken some particular metabolic pathway naturally (Mahraoui et al. 1994; Caro et al. 1995; Tranchant et al. 1997). While more than twenty different clones have been isolated as published (Chantret et al. 1994), we selected three well studied clones (TC7, PD7 and PF11) that were shown by Chantret et al. (1994) to exhibit noticeable differences.

A first key aspect to study was the viability of the three clones upon incubation of the apical side of the cell monolayer with mixed bile salt micelles. The first two methods used to evaluate cellular integrity, i.e. Phenol Red diffusion or nucleus labelling with propidium iodide, showed that the cell integrity of the three clones was not noticeably altered for several hours. Moreover, measurement of the cellular LDH activity release in the external medium, a very sensitive indicator of cell membrane 

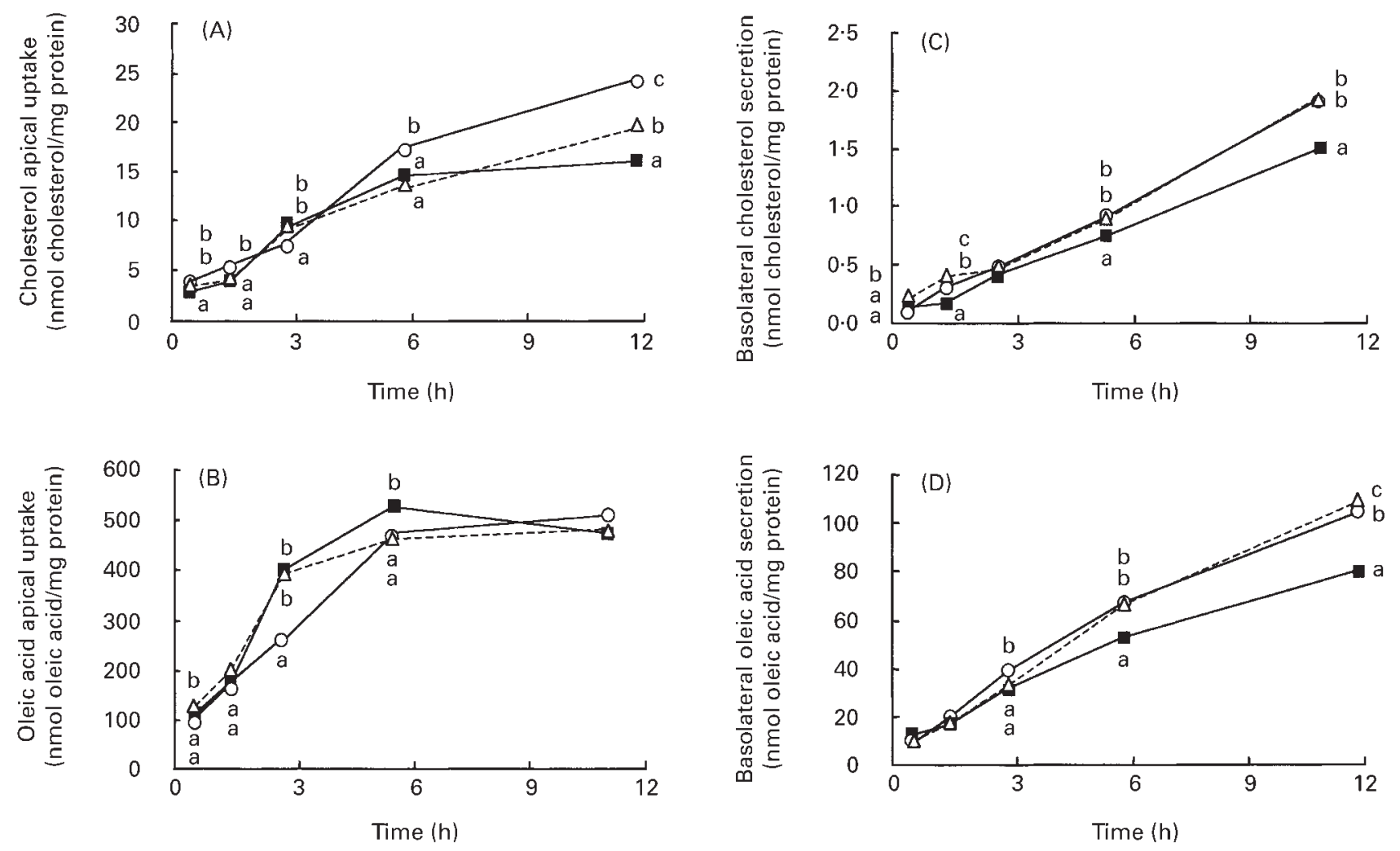

Fig. 3. Cholesterol and oleic acid uptake by Caco-2 clones: after $21 \mathrm{~d}$ culture with complete medium on filters, TC7 (-口-), PF11 (-O-) and PD7 $(-\Delta-)$ cells were incubated at their apical side with doubly radiolabelled mixed micelles at different times: $0.5,1.5,3.0,6.0$ and $12.0 \mathrm{~h}$. The basolateral medium consisted of Dulbecco's modified Eagle's medium with delipidated fetal calf serum. After incubation, basolateral media were removed and lipids extracted from cells. Radioactivity was measured on aliquots of cellular extracts and basolateral media. Proteins were solubilized from cells by $\mathrm{NaOH}$ and quantified by BCA kit (Pierce; Rockford, IL, USA). Cellular cholesterol (A), cellular oleic acid (B), basolateral cholesterol (C) and basolateral oleic acid (D) are expressed in $\mathrm{nmol} / \mathrm{mg}$ protein. For details of procedures, see $\mathrm{p}$. 212, Values are means for five replicates with standard errors shown by vertical bars. ${ }^{a, b, c}$ Mean values with unlike superscript letters were significantly different between clones $(P<0.05)$.

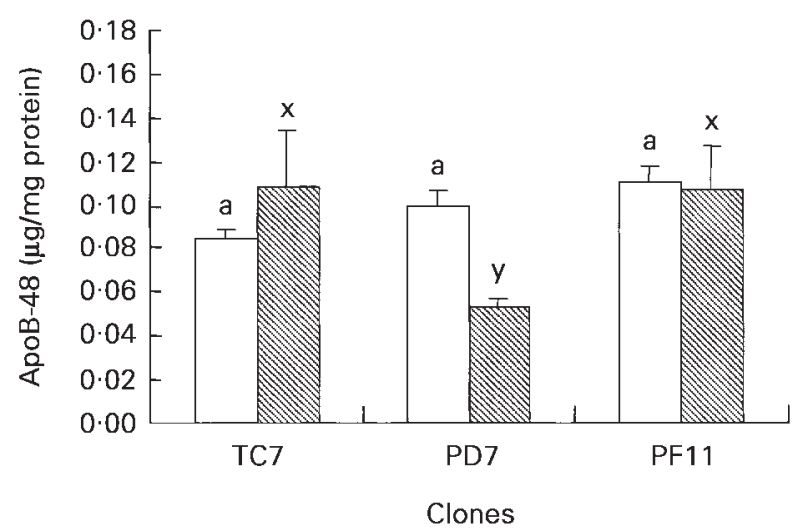

Fig. 4. Cellular and basolateral apolipoprotein (Apo) B-48. ApoB-48 concentration in cellular extracts $(\square)$ and basolateral medium $(\mathbb{Q})$ for TC7, PF11 and PD7 clones after $3.0 \mathrm{~h}$ mixed micelles apical incubation. Clones were cultured on filters in Dulbecco's modified Eagle's medium containing fetal calf serum $(200 \mathrm{ml} / \mathrm{l})$ and nonessential amino acids $(10 \mathrm{~g} / \mathrm{l})$ for $21 \mathrm{~d}$. Twenty-four hours before experiment, cells were preincubated with delipidated medium. ApoB-48 was quantified as described on p. 213 Values are means for five replicates with standard errors shown by vertical bars. ${ }^{a, b}$; ${ }_{x, y}$ Mean values with unlike superscript letters were significantly different at a given time point $(P<0.05)$.
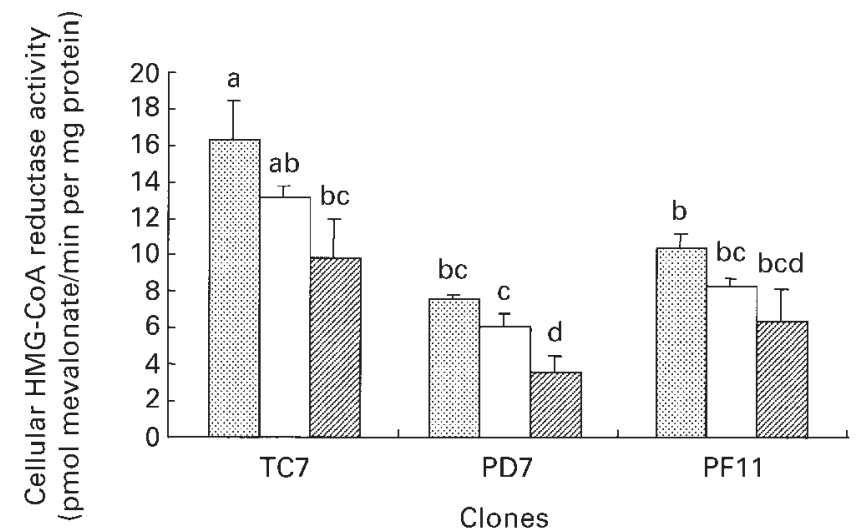

Fig. 5. 3-Hydroxy-3-methylglutaryl (HMG)-CoA reductase activity and cholesterol uptake. HMG-CoA reductase activity was measured in TC7, PD7 and PF11 clonal lines in basal conditions (國), after apical incubation with mixed micelles $(\square)$ or basal incubation with LDL (细). Clones were cultured on filters in Dulbecco's modified Eagle's medium containing fetal calf serum $(200 \mathrm{ml} / \mathrm{l})$ and nonessential amino acids $(10 \mathrm{~g} / \mathrm{l})$ for $21 \mathrm{~d}$. Cells were preincubated for $24 \mathrm{~h}$ before the experiment with medium without lipid. Cells were then incubated for $1.5 \mathrm{~h}$ with mixed micelles at the apical side or LDL at the basal side, and delipidated culture medium at the basolateral side or apical side respectively. HMG-CoA reductase activity was measured as described on p. 213. Values are means for five replicates with standard errors shown by vertical bars. ${ }^{a, b, c, d}$ Mean values with unlike superscript letters were significantly different between clones $(P<0.05)$. 
damage (Chong et al. 2000), indicates in fact that the TC7 clone accommodates the detergent environment better than the two other clones for several hours. Thus, the TC7 clone can particularly well reproduce the functionality of intestinal cell in vivo.

After a few hours incubation, the rates of micellar cholesterol apical uptake were comparable with the three clones, whereas significant differences were found after longer incubation time $(12 \cdot 0 \mathrm{~h})$. This indicates that the efficiency of the processes involved in brush border membrane dietary cholesterol uptake (Hauser et al. 1998) and/or subsequent processing is somewhat different. Nevertheless, given the absence of a marked difference between clones for exogenous cholesterol basolateral secretion, these clones cannot help to model the very large range $(35-80 \%)$ of intestinal cholesterol absorption rats observed in human subjects (Bosner et al. 1999). Conversely, the $3.0 \mathrm{~h}$ rates of oleic acid apical uptake were about 2-fold higher with the TC7 and PD7 clones than with the PF11, suggesting that this last clone could be partly deficient in some key pathway involved in fatty acid uptake or utilization (Hussain, 2000). In fact, after $3.0 \mathrm{~h}$ incubation in the present conditions, the net apical uptake (sum of cellular content and basolateral secretion) of oleic acid and cholesterol overall represented 86 and $21 \%$ of the incubated doses respectively, thus mimicking well the situation prevailing in human subjects, where the overall extents of intestinal absorption of dietary fatty acids and cholesterol are 97 and $55 \%$ respectively (Bosner et al. 1999).

Regarding the basolateral secretion of oleic acid and cholesterol, an almost linear time-dependence was observed with the three clones, the TC7 clone exhibiting lower figures for long incubation times $(6.0$ and $12.0 \mathrm{~h})$. The basolateral secretion measured after $1.5 \mathrm{~h}$ overall amounted for 9.7 and $6.8 \%$ of uptaken oleic acid and cholesterol respectively, the results obtained after $12.0 \mathrm{~h}$ being 20 and $9 \%$ respectively. This is noticeably higher than the value of 15 or $6 \%$ for oleic acid obtained after $20.0 \mathrm{~h}$ incubation of a monolayer made of cells of the parental Caco-2 line in comparable conditions (van Greevenbroek et al. 1996; Mehran et al. 1997). These results lead us to point out that the three clones could secrete exogenous lipids basolaterally better than the parental cell line which makes them more susceptible to reproduce the metabolic situation occurring in intestinal cells in vivo in man. It is noteworthy that most absorbed oleic acid is secreted in lipoproteins with low density $(\mathrm{d}<1.063 \mathrm{gV} \mathrm{ml}$ ) from the TC7 and PD7 clones as already observed with the parental Caco-2 cells (Mehran et al. 1997). Absorbed cholesterol is also better secreted in lipoproteins with low density by these clones. Because the PD7 clones secrete less ApoB-48 than the two other clones, the lipoproteins with low density secreted by this clone have a much higher dietary lipid and cholesterol content. This could result from some differences in the cell machinery responsible for lipidation of ApoB-48 and/or chylomicron secretion basolaterally (Hussain, 2000). Nevertheless, the lipoproteins with low density secreted by the three clones have comparable dietary lipid:cholesterol ratios.
The basal levels of intracellular HMG-CoA reductase activity, the rate-limiting enzyme in cholesterol synthesis (Brown \& Goldstein, 1980), were in the same order of magnitude as those measured on the heterogeneous parental line cells (Field et al. 1991). The three clones exhibited significantly different figures in the following decreasing order: TC7 $>$ PF11 $>$ PD7, with a 2-fold difference for extreme clones. The extent of enzyme down-regulation induced by apical micellar cholesterol was moderate and comparable in the three clones (about $20 \%$ ) and in agreement with values (about 15\%) reported for the parental line cells (Field et al. 1991). These comparable extents of down-regulation could be due to comparable rates of cholesterol apical uptake by the three clones under the conditions used ( $1.5 \mathrm{~h}$ incubation). This down-regulation was already shown to result from a reduced mRNA traduction and increased rate of enzyme degradation (Field et al. 1991).

As already observed in the parental cell line (Reimann et al. 1992), addition of LDL at the basal side of the clonal cells generated a marked down-regulation of HMG-CoA reductase activity, the PD7 clone showing the greatest $(-53.8 \%)$ reduction as compared with the two others (TC7: $-39.7 \%$, PF11 -39.0\%). Overall, under such conditions, the PD7 clone showed a 2.7-fold lower level of HMG-CoA reductase activity than the TC7 clone. Such differences in sensitivity to LDL cholesterol could result from different levels of the ApoB,E receptor at the basolateral membrane (Field et al. 1993) and/or intracellular machinery involved in the regulation of $\mathrm{HMG}-\mathrm{CoA}$ reductase activity (Brown \& Goldstein, 1980) in intestinal Caco- 2 cells. Because the small intestine is one of the key organs responsible for cholesterol synthesis in the body (Dietschy \& Gamel, 1971) the differences observed between clones regarding the basal levels and amplitude of down-regulation of cholesterol synthesis could be used to mimic situations characterized by different levels of cholesterol synthesis.

In conclusion, using some pure clones obtained from the human intestine $\mathrm{Caco}-2$ cell line proved to be an efficient way to study dietary lipid processing and have reproducible data in well-defined growth and cell viability conditions. In that respect the TC7 clone appears particularly suitable to accommodate the detergent environment as occurring in vivo. The clones can uptake exogenous cholesterol apically in the following order: TC $7<\mathrm{PD} 7<\mathrm{PF} 11$, with no marked difference for oleic acid uptake. TC7 clone secretes basolaterally less exogenous cholesterol and oleic acid while PD7 secretes less ApoB-48. Capacity for cholesterol synthesis is in the following order: PD7 $\leq$ PF1 $<$ TC7, with a marked down-regulation elicited by LDL in PD7. Taken together, these results show that these different clones provide a new tool to study the intestinal uptake and processing of dietary lipids in somewhat variable situations carefully, thus mimicking to some extent known interindividual variability.

\section{Acknowledgements}

This work received a research grant from RCL group (France) and the Provence-Alpes-Côte-d'Azur Council. 
The authors wish to thank M. Rousset and A. Zweibaum for the gift of TC7, PD7 and PF11 clones of the Caco-2 cell line.

\section{References}

Anderberg EK \& Artursson P (1993) Epithelial transport of drugs in cell culture. VIII: Effects of sodium dodecyl sulfate on cell membrane and tight junction permeability in human intestinal epithelial (Caco-2) cells. Journal of Pharmaceutical Sciences 82, 392-398.

Beaumier-Gallon G, Dubois C, Senft M, Vergnes MF, Pauli AM, Portugal H \& Lairon D (2001) Dietary cholesterol is secreted in intestinally derived chylomicrons during several subsequent postprandial phases in healthy humans. American Journal of Clinical Nutrition 73, 870-877.

Bosner MS, Lange LG, Stenson WF \& Ostlund RE Jr (1999) Percent cholesterol absorption in normal women and men quantified with dual stable isotopic tracers and negative ion mass spectrometry. Journal of Lipid Research 40, 302-308.

Brown MS, Dana SE \& Goldstein JL (1973) Regulation of 3-hydroxy-3-methylglutaryl coenzyme A reductase activity in human fibroblasts by lipoproteins. Proceedings of the National Academy Sciences, USA 70, 2162-2166.

Brown MS \& Goldstein JL (1980) Multivalent feedback regulation of $\mathrm{HMG} \mathrm{CoA}$ reductase, a control mechanism coordinating isoprenoid synthesis and cell growth. Journal of Lipid Research 21, 505-517.

Caro I, Boulenc X, Rousset M, Meunier V, Bourrié M, Julian B, Joyeux H, Roques C, Berger Y, Zweibaum A \& Fabre G (1995) Characterisation of a newly isolated Caco-2 clone (TC7), as a model of transport processes and biotransformation of drugs. International Journal of Pharmaceutics 116, 147-158.

Chantret I, Rodolosse A, Barbat A, Dussaulx E, Brot-Laroche E, Zweibaum A \& Rousset M (1994) Differential expression of sucrase-isomaltase in clones isolated from early and late passages of the cell line Caco-2: evidence for glucosedependent negative regulation. Journal of Cell Science 107, 213-225.

Chong MW, Gu KD, Lam PK, Yang M \& Fong WF (2000) Study on the cytotoxicity of microcystin-LR on cultured cells. Chemosphere 41, 143-147.

Dietschy JM \& Gamel WG (1971) Cholesterol synthesis in the intestine of man: regional differences and control mechanisms. Journal of Clinical Investigation 50, 872-880.

Dubois C, Beaumier G, Juhel C, Armand M, Portugal H, Pauli AM, Borel P, Latge C \& Lairon D (1998) Effects of graded amounts $(0-50 \mathrm{~g})$ of dietary fat on postprandial lipemia and lipoproteins in normolipidemic adults. American Journal of Clinical Nutrition 67, 31-38.

Field FJ, Born E \& Mathur SN (1997) Effect of micellar betasitosterol on cholesterol metabolism in CaCo-2 cells. Journal of Lipid Research 38, 348-360.

Field FJ, Fujiwara D, Born E, Chappell DA \& Mathur SN (1993) Regulation of LDL receptor expression by luminal sterol flux in Caco-2 cells. Thrombosis 13, 729-737.

Field FJ, Shreves T, Fujiwara D, Murthy S, Albright E \& Mathur SN (1991) Regulation of gene expression and synthesis and degradation of 3-hydroxy-3-methylglutaryl coenzyme A reductase by micellar cholesterolin CaCo- 2 cells. Journal of Lipid Research 32, 1811-1821.

Halleux C \& Schneider YJ (1991) Iron absorption by intestinal epithelial cells: $1 . \mathrm{CaCo} 2$ cells cultivated in serum-free medium, on polyethyleneterephthalate microporous membranes, as an in vitro model. In Vitro Cellular and Developmental Biology 27A, 293-302.

Hauser H, Dyer JH, Nandy A, Vega MA, Werder M, Bieliauskaite E, Weber FE, Compassi S, Gemperli A, Boffelli D, Wehrli E, Schulthess G \& Phillips MC (1998) Identification of a receptor mediating absorption of dietary cholesterol in the intestine. Biochemistry 37, 17843-17850.

Homan R \& Hamelehle KL (1998) Phospholipase A2 relieves phosphatidylcholine inhibition of micellar cholesterol absorption and transport by human intestinal cell line Caco-2. Journal of Lipid Research 39, 1197-1209.

Hussain MM (2000) A proposed model for the assembly of chylomicrons. Atherosclerosis 148, 1-15.

Levy E, Mehran M \& Seidman E (1995) Caco-2 cells as a model for intestinal lipoprotein synthesis and secretion. FASEB Journal 9, 626-635.

Lorec AM, Juhel C, Pafumi Y, Portugal H, Pauli AM, Lairon D \& Defoort C (2000) Determination of apolipoprotein B-48 in plasma by a competitive ELISA. Clinical Chemistry 46, $1638-1642$.

Mahraoui L, Takeda J, Mesonero J, Chantret I, Dussaulx E, Bell GI \& Brot-Laroche E (1994) Regulation of expression of the human fructose transporter (GLUT5) by cyclic AMP. Biochemical Journal 301, 169-175.

Mamo JC, Proctor SD \& Smith D (1998) Retention of chylomicron remnants by arterial tissue; importance of an efficient clearance mechanism from plasma. Atherosclerosis 141, Suppl. 1, S63-S69.

Mehran M, Levy E, Bendayan M \& Seidman E (1997) Lipid, apolipoprotein, and lipoprotein synthesis and secretion during cellular differentiation in Caco-2 cells. In Vitro Cellular and Developmental Biology 33, 118-128.

Pinto M, Robine-Leon S, Appay MD, Kedinger M, Triadou N, Dussaulx E, Lacroix B, Simon-Assmann P, Haffen K, Fogh J \& Zweibaum A (1983) Enterocyte-like differentiation and polarization of the human colon carcinoma cell line Caco-2 in culture. Biology of the Cell 47, 323-330.

Reimann FM, Herold G, Grosshans I, Rogler G, Fellermann K \& Stange EF (1992) Regulation of cholesterol metabolism and low-density lipoprotein binding in human intestinal Caco-2 cells. Digestion 51, 10-17.

Sehayek E, Ono JG, Shefer S, Nguyen LB, Wang N, Batta AK, Salen G, Smith JD, Tall AR \& Breslow JL (1998) Biliary cholesterol excretion: a novel mechanism that regulates dietary cholesterol absorption. Proceedings of the National Academy Sciences, USA 95, 10194-10199.

Tranchant T, Besson P, Hoinard C, Delarue J, Antoine JM, Couet C \& Gore J (1997) Mechanisms and kinetics of alpha-linolenic acid uptake in Caco-2 clone TC7. Biochimica et Biophysica Acta 1345, 151-161.

Trotter PJ, Ho SY \& Storch J (1996) Fatty acid uptake by Caco-2 human intestinal cells. Journal of Lipid Research 37, 336-346.

van Greevenbroek MM, Erkelens DW \& de Bruin TW (2000) Caco-2 cells secrete two independent classes of lipoproteins with distinct density: effect of the ratio of unsaturated to saturated fatty acid. Atherosclerosis 149, 25-31.

van Greevenbroek MM, van Meer G, Erkelens DW \& de Bruin TW (1996) Effects of saturated, mono-, and polyunsaturated fatty acids on the secretion of apo B containing lipoproteins by Caco-2 cells. Atherosclerosis 121, 139-150. 